Correction

\title{
Correction: The ratio of STAT1 to STAT3 expression is a determinant of colorectal cancer growth
}

\author{
Harini Nivarthi, ${ }^{1,2}$, Claire Gordziel ${ }^{3}$, Madeleine Themanns ${ }^{1,4}$, Nina Kramer, Markus \\ Eberl $^{6}$, Björn Rabe7, Michaela Schlederer ${ }^{1,8}$, Stefan Rose-John ${ }^{7}$, Thomas Knösel ${ }^{9}$, \\ Lukas Kenner ${ }^{1,8}$, Patricia Freund ${ }^{1,4}$, Fritz Aberger ${ }^{6}$, Xiaonan Han $^{10}$, Robert Kralovics ${ }^{2}$, \\ Helmut Dolznig ${ }^{5}$, Susanne Jennek ${ }^{3}$, Karlheinz Friedrich ${ }^{3}$ and Richard Morigg| ${ }^{1,4}$ \\ ${ }^{1}$ Ludwig Boltzmann Institute for Cancer Research, Vienna, Austria \\ ${ }^{2}$ CeMM Research Center for Molecular Medicine of the Austrian Academy of Sciences, Vienna, Austria \\ ${ }^{3}$ Institute of Biochemistry II, University Hospital Jena, Jena, Germany \\ ${ }^{4}$ Institute of Animal Breeding and Genetics, University of Veterinary Medicine Vienna, Medical University of Vienna, Vienna, \\ Austria \\ ${ }^{5}$ Institute of Medical Genetics, Medical University of Vienna, Vienna, Austria \\ ${ }^{6}$ Department of Molecular Biology, University of Salzburg, Salzburg, Austria \\ 7 Biochemical Institute, Christian-Albrechts-University Kiel, Kiel, Germany \\ ${ }^{8}$ Clinical Institute of Pathology, Medical University of Vienna, University of Veterinary Medicine Vienna, Vienna, Austria \\ ${ }^{9}$ Institute of Pathology, Ludwig-Maximilians-University Munich, Munich, Germany \\ 10 Division of Gastroenterology, Hepatology and Nutrition, Cincinnati Children's Hospital Medical Center, Cincinnati, OH USA \\ Published: September 18, 2018
}

Copyright: Nivarthi et al. This is an open-access article distributed under the terms of the Creative Commons Attribution License 3.0 (CC BY 3.0), which permits unrestricted use, distribution, and reproduction in any medium, provided the original author and source are credited.

This article has been corrected: In Figure 2d, the immunofluorescence pictures of Stat 1 of the cell line SW620 were accidentally duplicated to the HCT116 cell line. The corrected Figure 2d is shown below. The authors declare that these corrections do not change the results or conclusions of this paper.

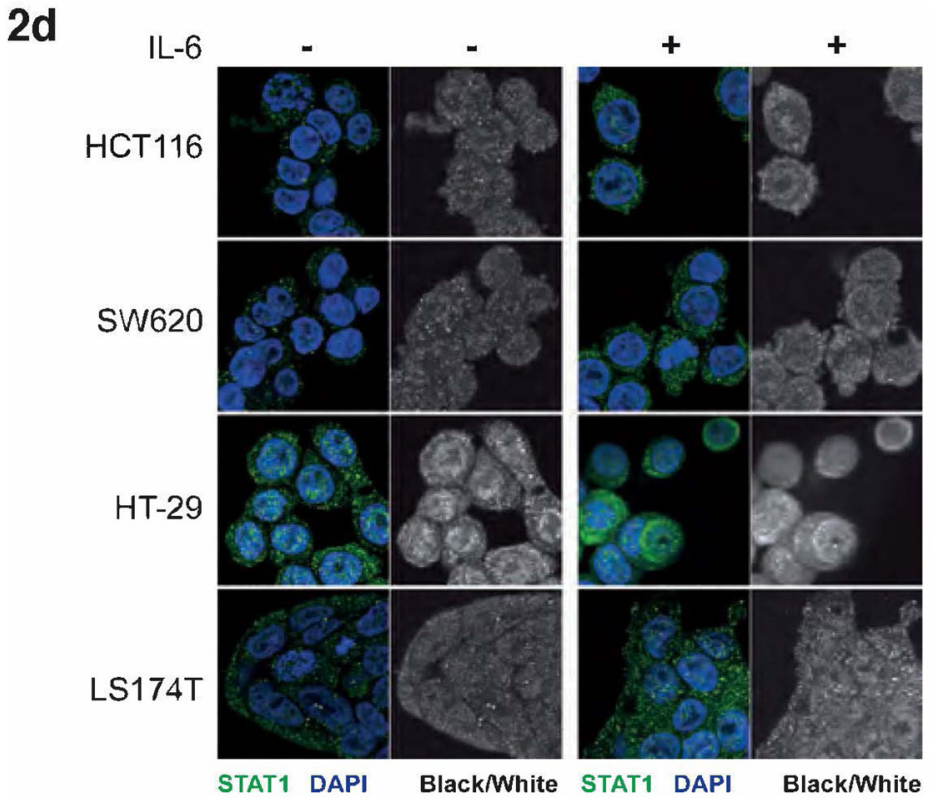

Figure 2: IL-6-dependent activation and subcellular localization of STAT3 and STAT1 in CRC cell lines. d. Immunofluorescence and confocal microscopy for detection of intracellular localization of STAT1.

Original article: Oncotarget. 2016; 7:51096-51106. https://doi.org/10.18632/oncotarget.9315 